\title{
QUANTUM HERMITE-HADAMARD INEQUALITIES FOR DOUBLE INTEGRAL AND $q$-DIFFERENTIABLE CONVEX FUNCTIONS
}

\section{Julalak Prabseang, Kamsing Nonlaopon And Jessada TARiboon}

Abstract. In this paper, we establish some new quantum analogue of Hermite-Hadamard inequalities for double integral and refinements of Hermite-Hadamard inequality for $q$-differentiable convex functions.

Mathematics subject classification (2010): 26D10, 26D15, 26A51.

Keywords and phrases: Hermite-Hadamard inequalities, $q$-derivative, $q$-integral, convex functions.

\section{REFERENCES}

[1] B. Ahmad And S. K. Ntouyas, Boundary value problems for q-difference inclusions, Abstr. Appl. Anal., 2011, 1 (2011).

[2] B. AhmAD, Boundary-value problems for nonlinear third-order q-difference equations, Electron. J. Differential Equ., 2011, 94 (2011), 1-7.

[3] N. Alp, M. Z. SARKAYA, M. Kunt And İ. İşCAN, q-Hermite Hadamard inequalities and quantum estimates for midpoint type inequalities via convex and quasi-convex functions, J. King Saud Univ. Sci. doi:10.1016/j.jksus.2016.09.007.

[4] G. BangerezaKo, Variational q-calculus, J. Math. Anal. Appl., 289, 2 (2004), 650-665.

[5] A. De Sole And V. G. KAC, On integral representation of $q$-gamma and $q$-beta functions, AttiAccad. Naz. Lincei Cl. Sci. Fis. Mat. Natur. Rend. Lincei (9) Mat. Appl., 16, 1 (2005), 11-29.

[6] S. S. Dragomir, Two refinements of Hadamard's inequalities, Coll. Sci. Pap. Fac. Kragujevac, 11, (1990), 23-26.

[7] S. S. DRAGOMiR, Some integral inequalities for differentiable convex functions, Contrib. Sec. Math. Tech. Sci., 13, (1992), 13-17.

[8] T. ERnst, The history of $q$-calculus and a new method, Department of Mathematics, Uppsala University, Sweden, 2000.

[9] H. Gauchman, Integral inequalities in q-Calculus, Comput. Math. Appl., 47, 2-3 (2004), 281-300.

[10] J. R. GRAEF AND L. KONG, Positive solutions for a class of higher-order boundary value problems with fractional q-derivatives, Appl. Math. Comput., 218, 19 (2012), 9682-9689.

[11] J. HADAMARD, Etude sur les propriétés des fonctions entiéres et en particulier d'une fonction considérée par Riemann, J. Math. Pures Appl., 9 (1893), 171-216.

[12] M. E. H. ISMAIL AND P. SimeOnov, $q$-Difference operators for orthogonal polynomials, J. Comput. Appl. Math., 233, 3 (2009), 749-761.

[13] F. H. JaCKSOn, On a q-definite integrals, Quart. J. Pure Appl. Math., 41 (1910), 193-203.

[14] F. H. JaCKson, q-Difference equations, Amer. J. Math., 32, 4 (1910), 305-314.

[15] V. KaC And P. Cheung, Quantum Calculus, Springer, New York, 2002.

[16] M. A. Noor, K. I. Noor And M. U. Awan, Some quantum estimates for Hermite-Hadamard inequalities, Appl. Math. Comput., 251 (2015), 675-679.

[17] M. A. Noor, K. I. Noor And M. U. Awan, Some quantum integral inequalities via preinvex functions, Appl. Math. Comput., 269 (2015), 242-251.

[18] B. G. PachPatte, Mathematical inequalities, Elsevier, 67, 2005.

[19] W. Sudsutad, S. K. NTOUYAS AND J. TARIBOON, Quantum integral inequalities for convex functions, J. Math. Inequal., 9, 3 (2015), 781-793. 
[20] S. TAF, K. BRAHIM AND L. RiAHI, Some results for Hadamard-type inequalities in quantum calculus, Le Matematiche, 69, 2 (2014), 243-258.

[21] J. TARIBOON AND S. K. NTOUYAS, Quantum integral inequalities on finite intervals, J. Inequal. Appl., 2014, 1 (2014), 121.

[22] J. TARIBOON AND S. K. NTOUYAS, Quantum calculus on finite intervals and applications to impulsive difference equations, Adv. Difference Equ., 2013, 1 (2013), 282.

[23] C. YU AND J. WANG, Existence of solutions for nonlinear second-order q-difference equations with first-order q-derivatives, Adv. Difference Equ., 2013, 1 (2013), 124. 